\title{
A data driven study of relationships between relief and farmland abandonment in a Mediterranean region
}

\author{
B. Zaragozí1 ${ }^{1}$ J. Rodríguez-Sala ${ }^{2}$, A. Rabasa ${ }^{2}$, A. Ramón ${ }^{1} \&$ \\ J. Olcina ${ }^{1}$ \\ ${ }^{1}$ Interuniversitary Institute of Geography, University of Alicante, Spain \\ ${ }^{2}$ Operations Research Centre, Miguel Hernández University, Spain
}

\begin{abstract}
The environmental, cultural and socio-economic causes and consequences of farmland abandonment are issues of increasing concern for researchers and policy makers. In previous studies, we proposed a new methodology for selecting the driving factors in farmland abandonment processes. Using Data Mining and GIS, it is possible to select those variables which are more significantly related to abandonment. The aim of this study is to investigate the application of the above mentioned methodology for finding relationships between relief and farmland abandonment in a Mediterranean region (SE Spain). We have taken into account up to 28 different variables in a single analysis, some of them commonly considered in land use change studies (slope, altitude, TWI, etc), but also other novel variables have been evaluated (sky view factor, terrain view factor, etc). The variable selection process provides results in line with the previous knowledge of the study area, describing some processes that are region specific (e.g. abandonment versus intensification of the agricultural activities). The European INSPIRE Directive (2007/2/EC) establishes that the digital elevation models for land surfaces should be available in all member countries, this means that the research described in this work can be extrapolated to any European country to determine whether these variables (slope, altitude, etc) are important in the process of abandonment.

Keywords: farmland abandonment, data mining, GIS, relief.
\end{abstract}




\section{Introduction}

Farmland abandonment is one of the most important landscape changes in the European Union, so this is why there have been many researches to achieve greater understanding of this phenomenon [1]. However, these studies have a number of difficulties not easily overcome. Abandonment researches must be integral, multiscale and take into account a large number of variables. Given the complexity of these processes and due to the need for understanding the impact of new policies, the EU is really interested in those scientific reports which define, calibrate and test models that explain landscape transformations in European agricultural areas [2]. In this context, future scenarios help us to understand relationships between different landscape elements and are commonly used as support for decision making.

Techniques for creating territorial scenarios should be agile and fast. This is why we analyze the new trends in creation and management of geographic information, as they enable the development of models and scenarios based uniquely on geographic databases. These useful models, which can be described as "datahungry" [3], are mainly affected by two problems: (1) they require integrating a large volume of information (different sources, formats, dates, scales, etc.) and (2) data management and interpretation is affected by several methodological shortcomings. In previous papers we presented a and tested a Data Mining method for generating rule based models [4]. This models are understood as a fast way for defining geographical hypothesis for particular regions. In this paper, our main goal is to use our rule mining approach for generating some hypotheses about how relief influences farmland abandonment. If this technique can discover relevant geographical knowledge for a particular region, we could think about applying it to analyze bigger regions with a multiscale approach.

The relief includes the group of physical variables more taken into account in land use change and farmland abandonment studies [1,5]. However, the results of different studies show considerable heterogeneity in patterns that relate these variables to the land use changes studied (e.g steepest slopes are usually related to abandonment, but in some particular landscapes this relationship is just the opposite. In addition, this some relationships may change at different scales). This heterogeneity, locally, may be related to landscape features that are not usually taken into account or the scale of study [1]. So then, in the study of farmland abandonment and the scenarios creation mentioned above, a new research is necessary to include new variables related to the relief.

\section{Farmland abandonment and relief in the study area}

The Marina Baja region is a well-known study area, described by several theses, papers and studies [4]. Based on this knowledge and the large volume of available geographic information, the Marina Baja is an ideal environment to test the creation of territorial scenarios based on geographic databases. Using this testbed we will be able to evaluate the results of the Data Mining experiment. Figure 1 
shows some general geographic details from this Mediterranean region, but now a more specific portrayal is done for the farmland abandonment process in the study area.

The evolution of the regional economy during the second half of the twentieth century was characterized by a shift from a traditional model based on agricultural activities into a modern society, where tourism and urbanization are the main engines of economy. This economic development has contributed to prosperity and wealth. However, the end of traditional activities has led to increase many regional imbalances [6].

The main imbalance in the study area is reflected in the fact that $90 \%$ of the workforce in the region is in the service or construction sectors. Tourism is the main economic activity, but maintains a precarious balance and strong competition with other land-consuming activities [6]. However, despite the profound changes described, farming continues to have a crucial importance in this Mediterranean region. This importance should be measured not only in its economic and productive dimensions, but also in terms of the social, cultural and environmental benefits.

More specifically, the farming activity of this region is affected by three factors. Firstly, the average size of farms is less than one hectare and often it does not exceed $2000 \mathrm{~m}^{2}$. This is due to a family-based agriculture and some cultural factors. In addition, the high price of land in the spaces near urban areas is also a barrier to the parcel aggregation that could solve this weakness. The owners often prefer to leave the activity and keep the plots. This is due to expectations of benefit from urbanization on rural land. Agricultural cooperatives have been able to mitigate this problem to some extent. However, there are no alternatives to the joint use of lands, which would increase the profitability of agriculture and could prevent abandonment. Ultimately, the viability of the current model of small family farms is compromised by poor generational replacement. The part-time farming is no longer considered an attractive option because of low profit margins, and the expectations generated by the processes of urban transformation [7].

Secondly, the structural water deficit endangers the viability of farms and other economic activities [7]. In this context, irrigated agriculture consumes large volumes of water and this is a big conn in the political and social debate on the rational use of water resources. The construction and tourism sectors compete with agriculture for water use. In the last two decades, the modernization of irrigation systems has become completely necessary in the Marina Baja. However, there are new problems arising from the change of irrigation systems, construction of the necessary infrastructure, and finally, the abandonment of traditional structural elements, such as ditches, rafts or channels.

The socio-economic profile of farmers is characterized by a high average age and their knowledge comes mainly from experience. According to the agricultural census of 2009, it seems that this is changing with the emergence of young farmers with higher education. Moreover, farmers tend to keep the land even after retirement age. The reasons to continue the activity beyond retirement may be the "attachment to land" or for achieving extra incomes [7]. The most likely scenario 

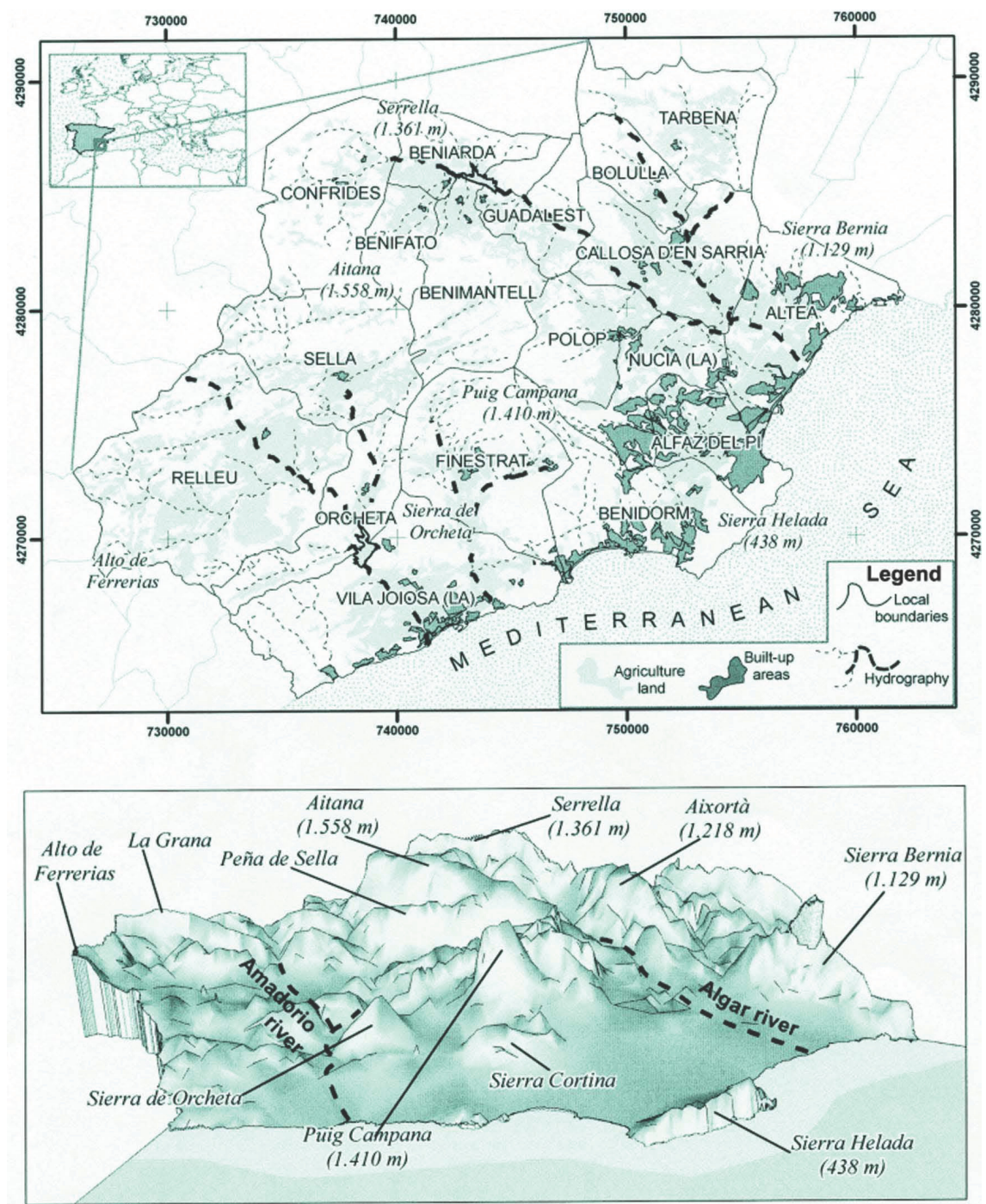

3D Representation of Marina Baja Region

Figure 1: The geographic context in the Marina Baja region.

in the short to medium term comprises a lack of generational replacement on farms, which would mean a continuation of the process of abandonment started in the last decade.

The above factors have existed for several decades. However, an excellent performance provided by irrigated agriculture made it possible to keep the most productive lands. In spite, in recent years, urban expansion processes, typical of coastal tourist areas, have been extended to affect inland municipalities where 

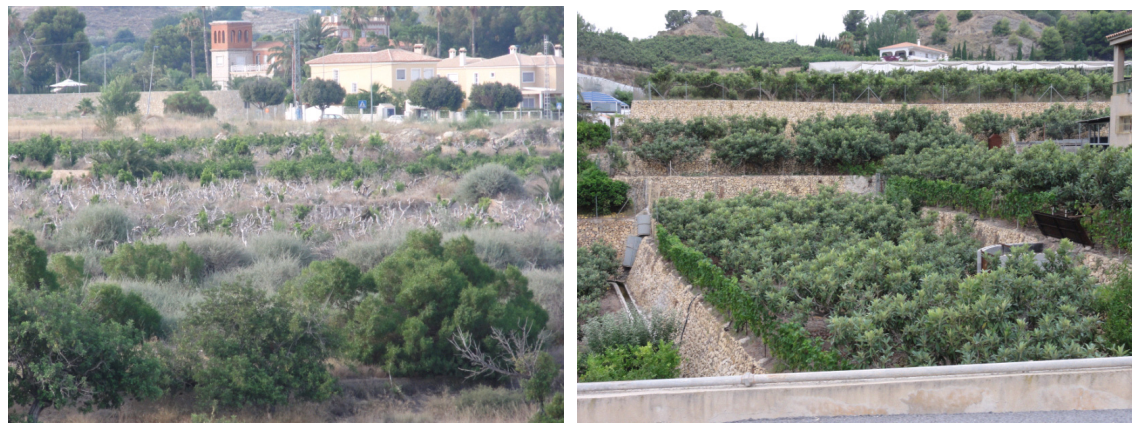

Figure 2: In the study area abandonment is more related to the flat areas.

there is less pressure on land use, greater land availability and lower prices. In the Marina Baja, this process is more evident in the municipalities of La Nucia and Finestrat, where agricultural lands are now completely unprotected from the speculative real estate investments. On the other hand, a complementary process has led to the tillage of new agricultural lands, normally to areas further inland, creating more competitive farms, technologically advanced and away from land use pressures. These new farms are related to a professionalisation of agriculture, far away from traditional agricultural activities [7]. Governmental statistics are helpless for showing the consequences of these new agricultures and creating future scenarios will require a deep geographical study. Thus, considering the particular relief of this region and the urbanization-agriculture duality, the Marina Baja could be divided in five areas: (1) Coastal zones with lower slopes, where the agriculture is almost abandoned, (2) flat inlands that are also affected by the urbanization processes, (3) hills with beautiful panoramic views (coastal or not) of interest for real estate investments, (4) productive inlands not in competence with other land uses and (5) unproductive lands.

As a summary, the ultimate cause of farmland abandonment would be low yields produced by several commercial and economic reasons [7]. While these trends remain, restructuring processes will continue worsen the situation of the traditional family-based agriculture, which has been reduced in a significant way in the last decade. According to the agricultural census of 2009, in the last decade abandonment has ranged from $23 \%$ in the municipality of Callosa d'En Sarria and $59 \%$ of La Nucia.

Anyway, whether if we intend to mitigate the negative effects of abandonment, or if it would be profitable to restore the most productive plots, knowledge of this phenomenon is necessary to successfully create future and useful scenarios.

\section{Data and methods}

Nowadays, the lack of data should not be a problem in data-driven geographic modelling. The EU provide access to a large volume of geographic information 


\section{Profile curvature}

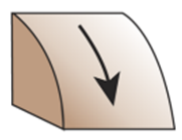

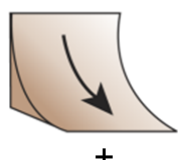

$+$

Plan curvature

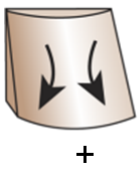

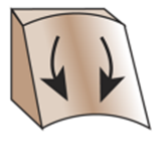

$-$
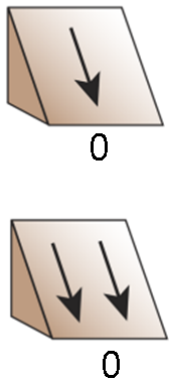

Figure 3: Visual explanation of the curvature variables (plan and profile).

through Spatial Data Infrastructures (SDI) that come under the INSPIRE directive (Directive 2007/2/EC of the European Parliament and of the Council of 14 March 2007, Establishing an Infrastructure for Spatial Information in the European Community). In our case study, we only used two products from the regional SDI at the Institut Cartografic Valencia website (http://www.icv.gva.es). We used the cadastral parcels vector layer and the Digital Elevation Model $(1 / 5,000)$ Then we analyzed it by calculating several geomorphometric indices which may influence agriculture [8].

The geomorphometric indices calculated for the study area can be grouped in four groups [8]: Basic morphometric, Hydrological, Climatic and Visibility indices. Among this group, different variables were obtained using SAGA GIS software (www.saga-gis.org). Figure 5 lists all variables that have been integrated into the Data Mining study.

Among the basic morphometric variables the average slope or orientation have been calculated since they are commonly used in the various studies on farmland abandonment [2]. We have also calculated some variables useful for describing landforms. The profile curvature is measured parallel to the direction of maximum slope. Figure 3 shows that a negative value of the curvature profile indicates that the surface is upwardly convex. Conversely, a positive value indicates that the surface is upwardly concave. Finally, a zero value indicates that the surface is linear. The profile curvature affects the acceleration or deceleration of the flow through the slope and therefore influencing the erosion and deposition [9].

The plan curvature is measured perpendicular to the direction of maximum slope. In this case a positive value indicates that the surface is convex laterally. Conversely, negative plan curvature indicates that the surface is laterally concave (see Figure 3). Finally, just as in the profile curvature, a null value indicates that surface is linear. The plan curvature refers to the convergence and divergence of the flow through a surface [9]. 


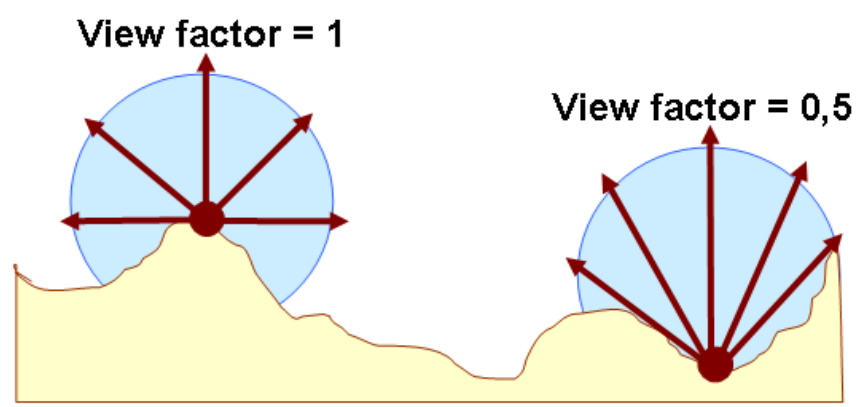

Figure 4: Visual explanation of the Sky View Factor.

A combination of both curvatures indices provide more precise description of the flux through a surface. The combination of flat and profile curvature allowed us to calculate a well-known landform classification [10].

Another measure calculated in this section is the convergence index. This index proposed by [11] describes the convergence of the flow in a slope. This is similar to the flat curvature, but not dependent on the absolute height difference.

Some hydrological variables were also calculated. The vertical distance of each point to the drainage system or the base level of the hydrographic network are very useful in the parameterization of the processes related to the distribution of soils [11]. Low values of these variables often characterize accumulation areas, while mean values indicate material transfer processes on the slopes, and the highest values occur in erosion areas. We also calculated the Downslope Distance Gradient and the Topographic Wetness Index [8]. The Topographic Wetness Index quantifies the role of topography in the redistribution of water in the landscape. This index takes values between 3 (steep, narrow areas) and 20 (wide and flat areas).

As for the climatic variables, the Diurnal Anisotropic Heating [11] and two indices of exposure-protection to the wind (Wind Effect and Effective Air Flow Height) were calculated for the four main compass points [12].

Finally, the analysis of visual landscape is costly to perform, so we only included variables related to visibility. Taking into account these variables in our Data Mining analysis can help us to evaluate, at a minimum cost, a more detailed landscape quality analysis is required. Thus, we calculated the Sky View Factor, Terrain View Factor and the Visible Sky (\%) [11].

Once all these variables were extracted at the cadastral parcel level, we performed a rule mining analysis using our Data Mining methodology and a previously created database on farmland abandonment [4]. The rule mining algorithm performs an adaptive variable selection which highlights those variables and variable combinations that are more related to abandonment. 


\section{Results and discussion}

According to the assumptions outlined in scientific literature, the best abandonment models are those which include different types of variables [4]. In this sense, our rule mining analysis has created a wide ruleset using different types of geomorphometric variables (basic, hydrological, climatic and visibility). The most significant rules combining these variables have been synthesized in figures 5 and 6 . Figure 5 shows how frequent are all these variables in the most significant rules, while Figure 6 shows the most common values taken by these variables when considering abandonment.

In the literature on farmland abandonment, mean elevation is possibly the most important variable of this group. However, for our case study this variable does not appear to be so important for explaining abandonment and variables derived from it provide a more interesting for the study of this area.

The data mining method can easily dismiss ten variables which do not seem to be related to farmland abandonment. For example, the Channel Network Base Level does not seem to describe any aspect of interest for agriculture in the region. Obviously, this is an hydrologic index. Considering that agriculture in the Marina Baja has specific elements, such as terracing or structural elements that affect the behavior of the runoff, and allow agriculture in unfavorable areas, so it is normal that these variables become less decisive in our analysis. Similarly, the Multiresolution Index of the Ridge Top Flatness is referred to areas of the county that do not allow agriculture.

The Multiresolution Index of Valley Bottom Flatness provides similar information to the Topographic Wetness Index. These two indices help to select plains and wide areas on the slopes or valleys. The Topographic Wetness Index does not provide information at multiple scales, but it is easier to perform an interpretation.

The slope has also been quite critical part of almost $90 \%$ of the best rule sets. The most repeated values of slope (see Figure 6) support our hypothesis: abandonment in flat areas (low or very low slope) may be related to the urbanization process and with greater proximity to urban areas. In contrast, the Marina Baja comprises steep slope areas which are among the most productive landscapes (see Figure 2). This attribute should be analyzed together with a more diverse set of variables (demographic, accessibility, among others) but its behaviour is promising for describing and analyzing abandonment in the Marina Baja region.

The two indices calculated to determine exposure to the winds have been revealing. Both variables are more related to abandonment when its components are calculated for east and south orientations. Moreover, in Figure 6 we can appreciate a higher ratio of abandonment when those areas experience lower wind effect. This relationship is not necessarily due to agronomic factors but may be caused by the above mentioned land pressure. This means that residential processes show preferences for those slopes facing the Mediterranean, while the 


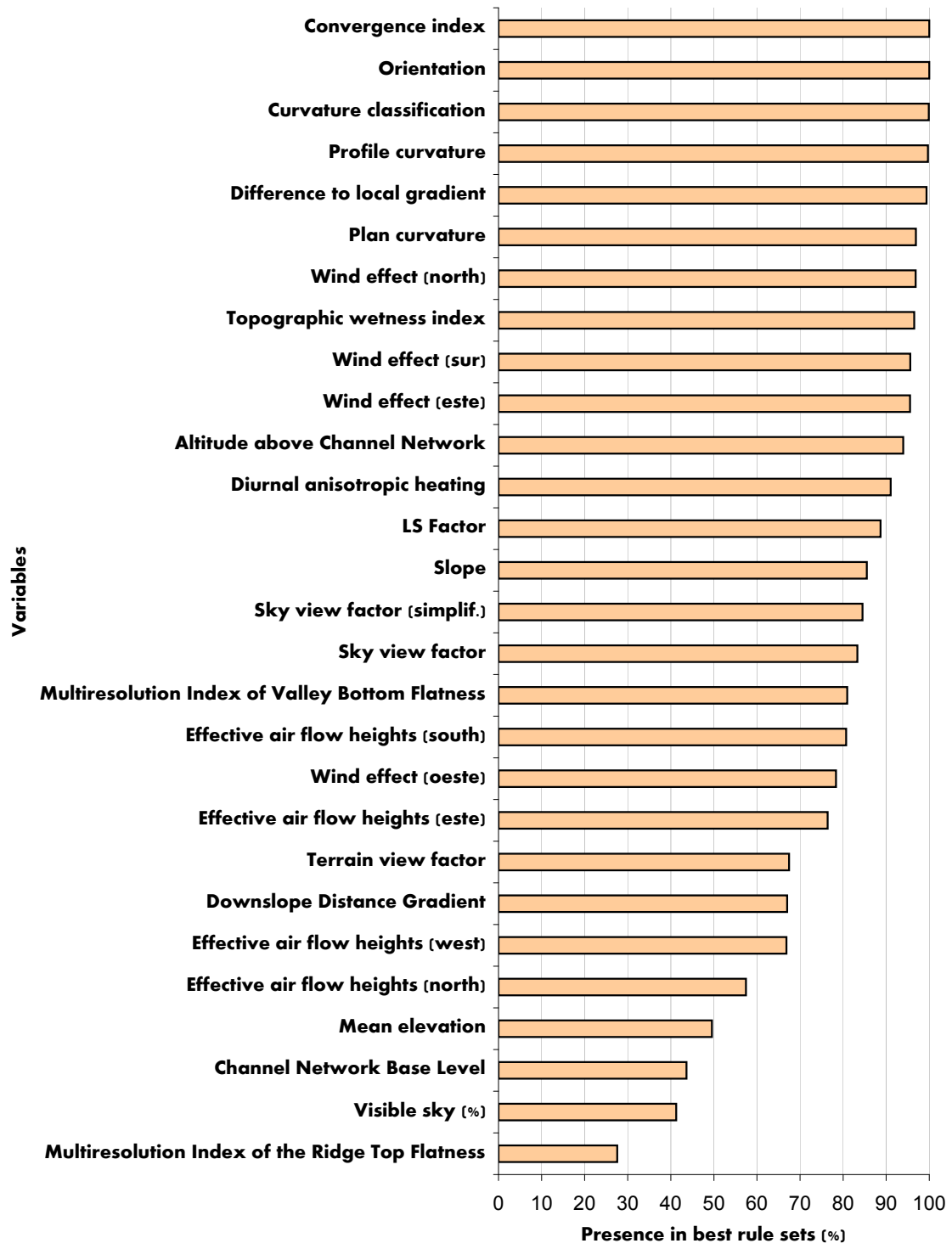

Figure 5: All variables calculated and how frequently they appeared in farmland abandonment relationships (rule sets).

remaining cold and gloomy agricultural valleys could be abandoned as a result of low productivity.

Orientation also appears to be important. However, the automatic discretization into 5 groups does not seem appropriate to give clear results. The orientation was 


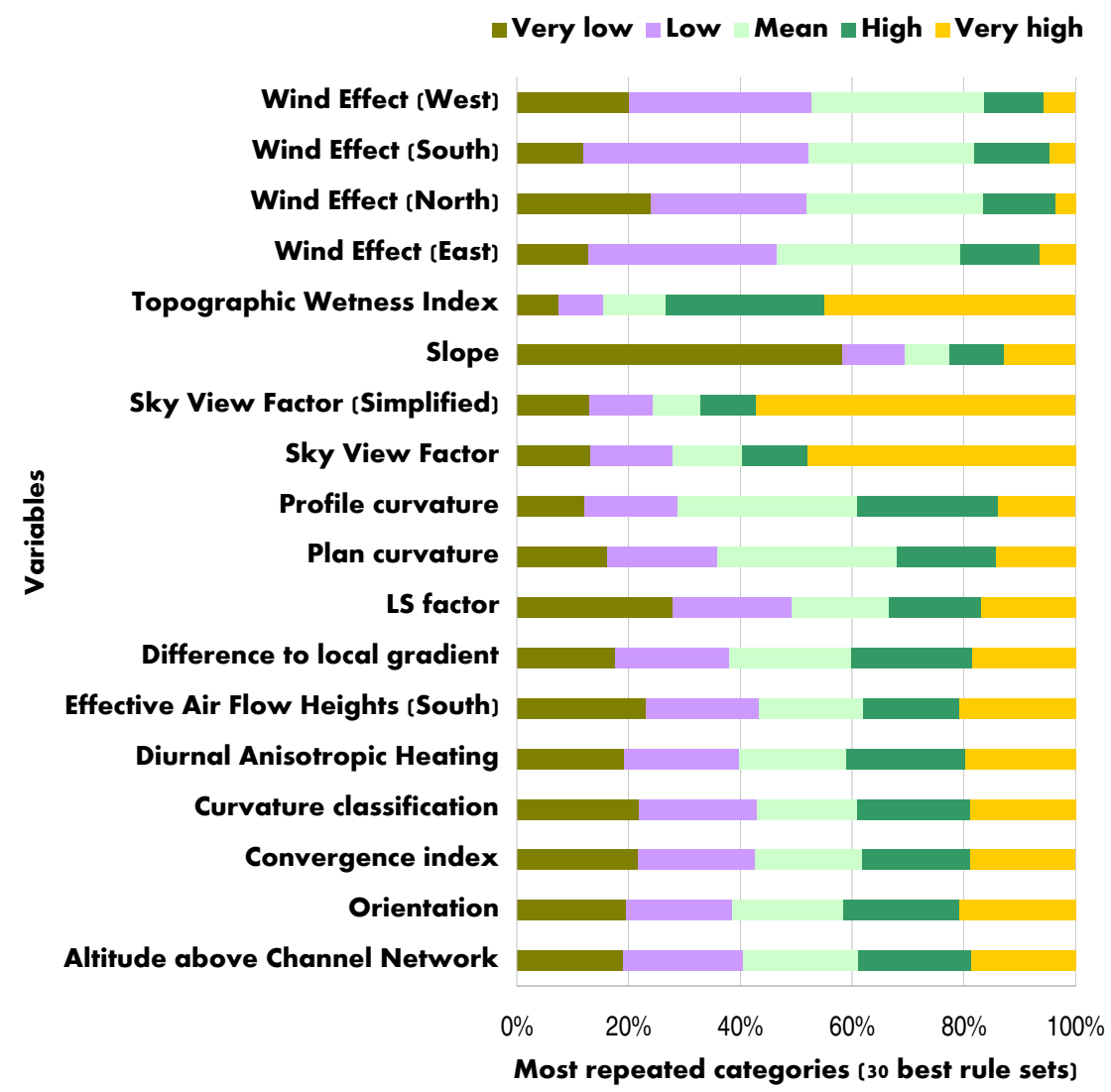

Figure 6: Most repeated values and how frequently they appeared in farmland abandonment relationships (rule sets).

calculated in degrees, so only a supervised classification could ensure a correct interpretation of the rule mining analysis.

The LS factor indicates a subtle relationship between abandonment and plain areas (see Figure 6). Despite other variables analysed, farmers in the Marina Baja would prefer to keep the flat lands but those are normally close to the urbanized areas. Again, it is obvious that a better data based model should incorporate variables from other groups [4].

Among the visibility variables, the sky visibility factors have been the most important. Their interpretation is quite simple: the most prominent areas (with higher visibility) seem to be more related to farmland abandonment. In the Marina Baja, these areas show a strong land use competition or a poor accessibility.

Finally, the rest of the basic variables describing the curvature and landforms certainly have proved to be important in Figure 5, but there is not a clear 
interpretation and a further analysis will be needed for incorporating more geographical variables to the Data Mining analysis.

\section{Conclusions}

We have emphasized that farmland abandonment is present worldwide. Since this phenomenon has different causes and consequences in each territory, the study should not be the same in all regions. Also, it has been found that there are many variables and variable groups involved.

Despite the difficulties in the study of farmland abandonment, in the literature review we found that about ten variables are identified to be the most important in explaining farmland abandonment in the overall context of the EU. Among these ten variables, the farmers age, the farm size and accessibility are considered the most relevant. These premises can save a good effort in modelling, but they will not have the same relevance in all regions. Therefore, the variable selection process is a key research topic. Scenarios of farmland abandonment should be developed using agile tools and we consider proven that an inductive approach based on available geographic data could help to perform a variable selection specific to each territory in the EU.

In this paper we have applied a novel Data Mining method based on commonly available geographic data. Thus, it has been shown how a data driven methodology can help in the selection of the most interesting variables related to farmland abandonment. In the near future, this methodology will enable a better use of the huge amount of data available in official databases.

\section{References}

[1] Gellrich, M., Baur, P., Koch, B. \& Zimmermann, N.E., Agricultural land abandonment and natural forest re-growth in the Swiss mountains: A spatially explicit economic analysis. Agriculture, Ecosystems \& Environment, 118(1-4), pp. 93-108, 2007.

[2] Renwick, A., Jansson, T., Verburg, P.H., Revoredo-Giha, C., Britz, W., Gocht, A. \& McCracken, D., Policy reform and agricultural land abandonment in the EU. Land Use Policy, 30(1), pp. 446-457, 2013.

[3] Parker, D.C., Hessl, A. \& Davis, S.C., Complexity, land-use modeling , and the human dimension : Fundamental challenges for mapping unknown outcome spaces. Geoforum, 39, pp. 789-804, 2008.

[4] Zaragozí, B., Rabasa, A., Rodríguez-sala, J.J., Navarro, J.T., Belda, A. \& Ramón, A., Modelling farmland abandonment : A study combining GIS and data mining techniques. Agriculture, Ecosystems \& Environment, 155, pp. 124-132, 2012.

[5] Temme, A. \& Verburg, P., Mapping and modelling of changes in agricultural intensity in Europe. Agriculture, Ecosystems \& Environment, 140(1-2), pp. 46-56, 2011. 
[6] Ivars Baidal, J.A., La planificación turística de los espacios regionales en España. Tesis doctoral, Universidad de Alicante, 2001.

[7] Noguera Tur, J., Viabilidad y competitividad del sistema citrícola valenciano. Boletín de la Asociación de Geógrafos Españoles, (52), pp. 81-99, 2010.

[8] Wilson, J.P., Gallant, J.C., Hutchinson, M.F., Repetto, P.L., Snyder, R.D. \& Krysanova, V., Terrain Analysis. Principles and Applications. John Wiley \& Sons Inc.: New York, p. 479, 2001.

[9] Tarboton, D.G., A new method for the determination of flow directions and upslope areas in grid digital elevation models. Water Resources Research, 33(2), pp. 309-319, 1997.

[10] Dikau, R., Entwurf einer geomorphographisch-analytischen Systematik von Reliefeinheiten. Heidelberger Geographische Bausteine, Heft 5, p. 50, 1988.

[11] Böhner, J. \& Antonic, O., Land-Surface Parameters Specific to TopoClimatology. Geomorphometry: Concepts, Software, Applications, eds. T. Hengl \& H.I. Reuter, Elsevier: Amsterdam, volume 33, chapter 8, pp. 195226, 1st edition, 2009.

[12] Dietrich, H. \& Böhner, J., Cold air production and flow in a low mountain range landscape in Hessia (Germany). Hamburger Beiträge zur Physischen Geographie und Landschaftsökologie, 19, pp. 37-48, 2008. 